\section{RISUS}

Journa

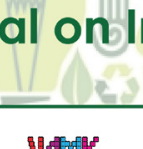

WAN

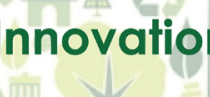

(5SN2179-3565

RISUS - Journal on Innovation and Sustainability Volume 6, número $1-2015$ ISSN: 2179-3565

Editor Científico: Arnoldo José de Hoyos Guevara Editora Assistente: Letícia Sueli de Almeida Avaliação: Melhores práticas editoriais da ANPAD

\title{
Diversity and Innovation: Empowering Women Fosters Innovation
}

\author{
Yuko Hayashi \\ Graduate School of Innovation and Technology Management, \\ Yamaguchi University \\ Address: 1677-1 Yoshida, Yamaguchi, 753-8511, Japan \\ E-mail: hayashiy@yamaguchi-u.ac.jp
}

\begin{abstract}
Women's participation in labor market is required to utilize diverse variety of talent. In Japan, females are not participating in the labor market yet, especially in policy/decision making positions although the legislation has progressed slowly. There are many potentials that might achieve a remarkable improvement in terms of innovation growth and productivity by incorporating the female labor force in the Japanese economy.

Women's active participation to economy is one of the pivotal economic growth strategies of Japanese government in 2013. The government is aiming to attain the target of $30 \%$ of women's participation in policy/decision making process by year 2020. However, only two categories attained that target number, pharmacists and member of the councils for national government. In order to win the objective in seven years, more positive actions will be needed.

This paper explorers why females are needed in the Japanese labor market, how extent women improve corporate performance and economy, and how women's diversity fosters product innovation and process innovation. Materials used for analysis are related government papers, books, and journals. Some interviews with business executives were conducted.
\end{abstract}

Keywords: diversity, women's matter, innovation, positive action, gender gap 


\section{INTRODUCTION}

World economy moves quickly and market changed day by day. To survive through the bustling world, diverse human resource should be utilized appropriately as a human capital portfolio. The then U.S. Secretary of States Hillary Clinton said at APEC Women and the Economy Summit 2011 "Unlocking the potential of women by narrowing the gender gap could lead to a 14-percent rise in per capita incomes by the year 2020." Christine Largarde, director of the international Monetary Fund, delivered the speech during the annual meetings of the IMF \& the World Bank Group held in Tokyo 2012, "Women could save Japan's economy if more of them went to work."

Women's participation is essential in order to boost economy in a short term and a long term.

\section{WHY DOES ECONOMY NEED WOMEN?}

\section{A declining birth rate and work force}

Exhibit 1 shows female work force participation rate by some OECD countries. Japanese women's work force participation rate in age group from 25 to 54 years old ranks 22nd among 30 OECD countries. In Japan and Korea, in age group from 30-34 years old, the female work force participation rate declines sharply. In this age group, women tend to give birth after marriage and retire their jobs and raise their children at home. After children are raised up, mothers go back to jobs or try to find new jobs so that a job participation rate increases again around age 40-49 though it is difficult to take good occupations as before they retired. Consequently, the line graph forms M-shaped. This tendency cannot be seen in other countries below. In Sweden, during the age group 30-34, female work force participation rate increase in contrast.

Recently, Japan's work force decline about a million people per year because of a low birth rate and retiring the baby boom generation. Total population is declining since 2011 due to the diminishing birthrate so that demographic structure in Japan changes to the ageing society. 2.6 people in working generation are supporting the one elderly person now. Declining work force might give a good chance for non-working women. As about 3.42 million female from 25 -to 49 years old want to have jobs, they have a possibility to compensate for the reduction of the labor, if they could. 
Exhibit 1: Female work force participation rate by countries

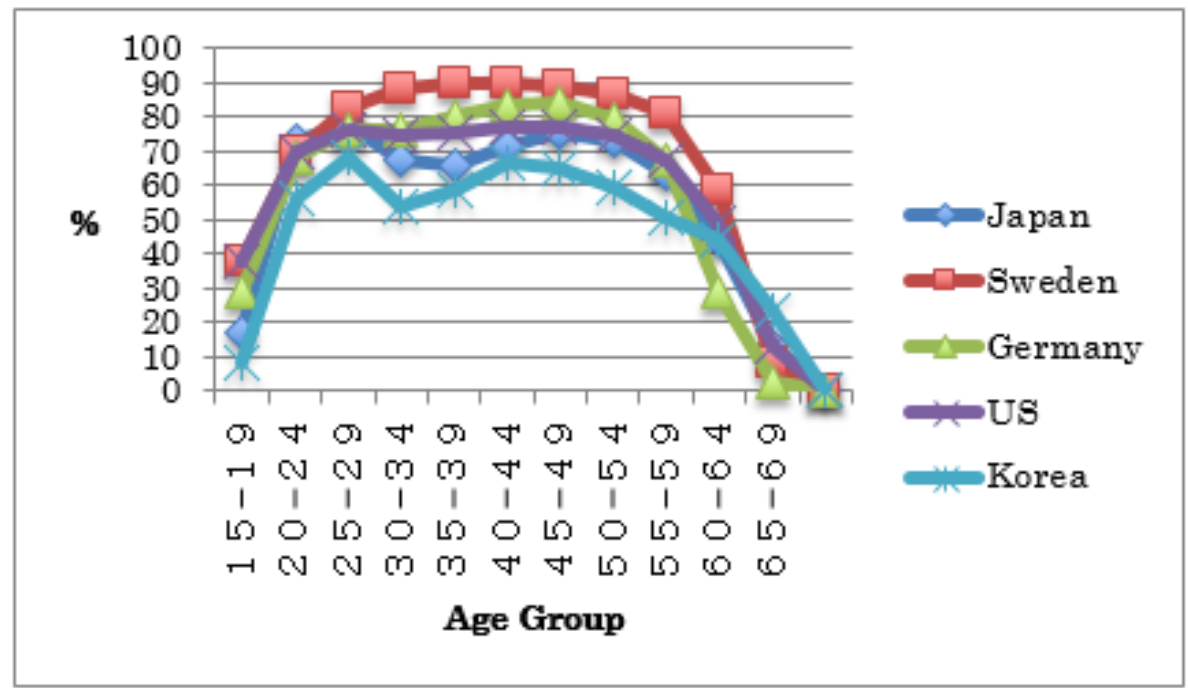

Source: Statistics Bureau, Ministry of Internal Affairs and Communication (2011) and ILO LABORSTA

Among the OECD countries, there are some countries, such as Italy, Korea, and Japan that have a low birth rate. Those countries tend to face the serious concerns of falling birth rate and rapid aging population coming with demographic changes.

Consequently, some worry when female goes to work and does not stay home, birth rate might diminish more. However, as Exhibit 2 shows, it is not true in OECD countries.

Relations between women's employment rate and birth rate have not been studied profoundly. There are some hypothesis why a birth rate does not decline when women have jobs in developed countries. First, when a husband and wife work together, total income of the family increases so that they can have more stable finance plan for raising children.

Exhibit 2: Women's Employment rate and Birth rate in OECD countries

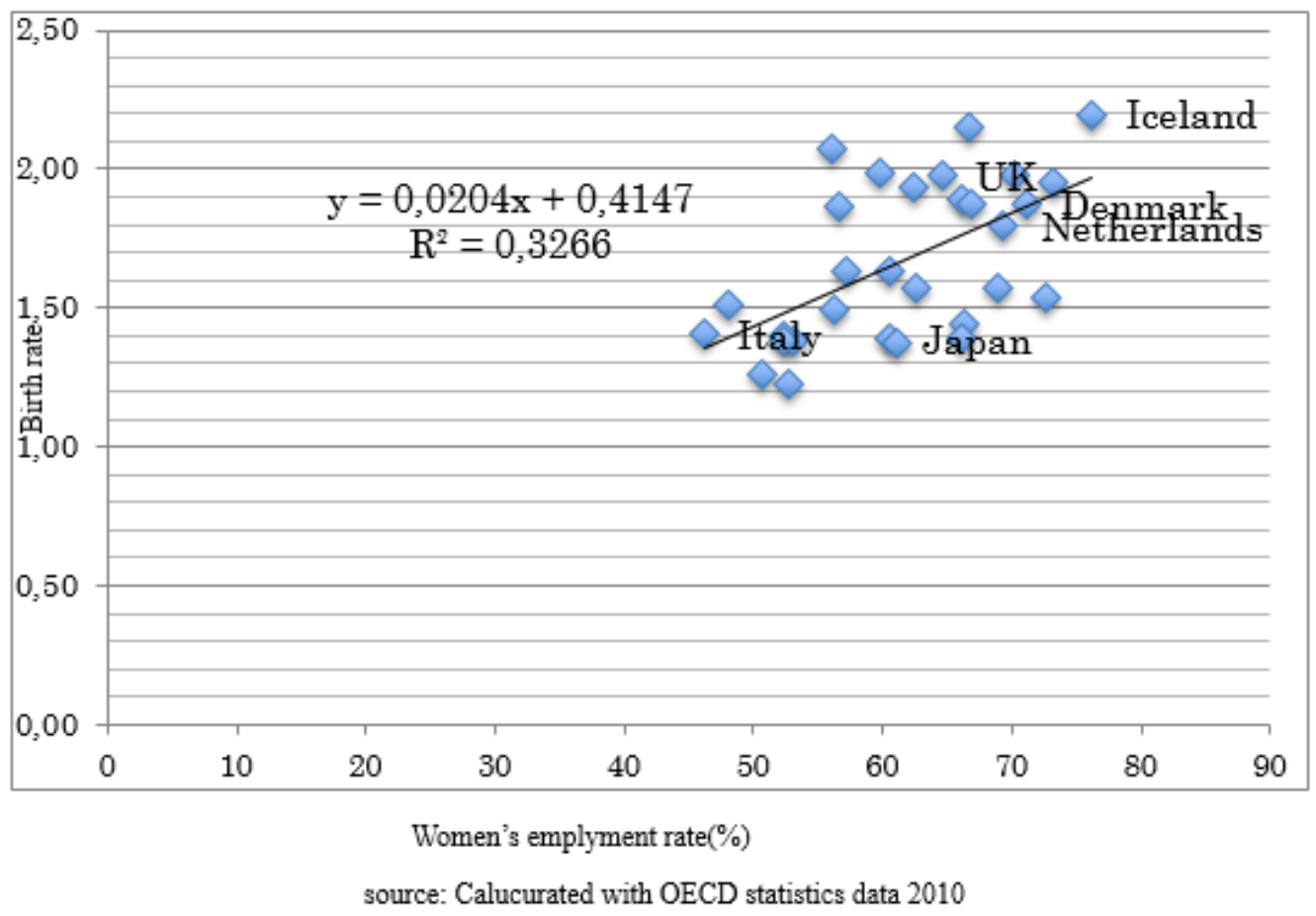


At the same time, when the one loses a job, the other partner support family expense. Second, a country which is able to provide substantial public supports for working women, could provide supports for raising childrens so that working woman wuold have more children.

Some economic indexes show women's contribution to improving business performance

Countries and companies should deploy people effectively in order to obtain a sustainable competitiveness. However, it is not certain that how extent the profit would expand when the employment of women is expanded. A report of Goldmansachs says "in many countries where there is already a high proportion of educated women who are not working, the potential economic boost from employing more of them does not necessarily come at a significant cost. Greater female employment has direct implications for household disposable income and savings, which have a trickle-down effect in terms of higher spend on education and health."

Exhibit3 shows when the women's employment rate goes up, the GDP per capita goes up in OECD countries. When a woman works, total income per family increases and disposable income increases as well.

Exhibit 3: Women's employment rate and GDP

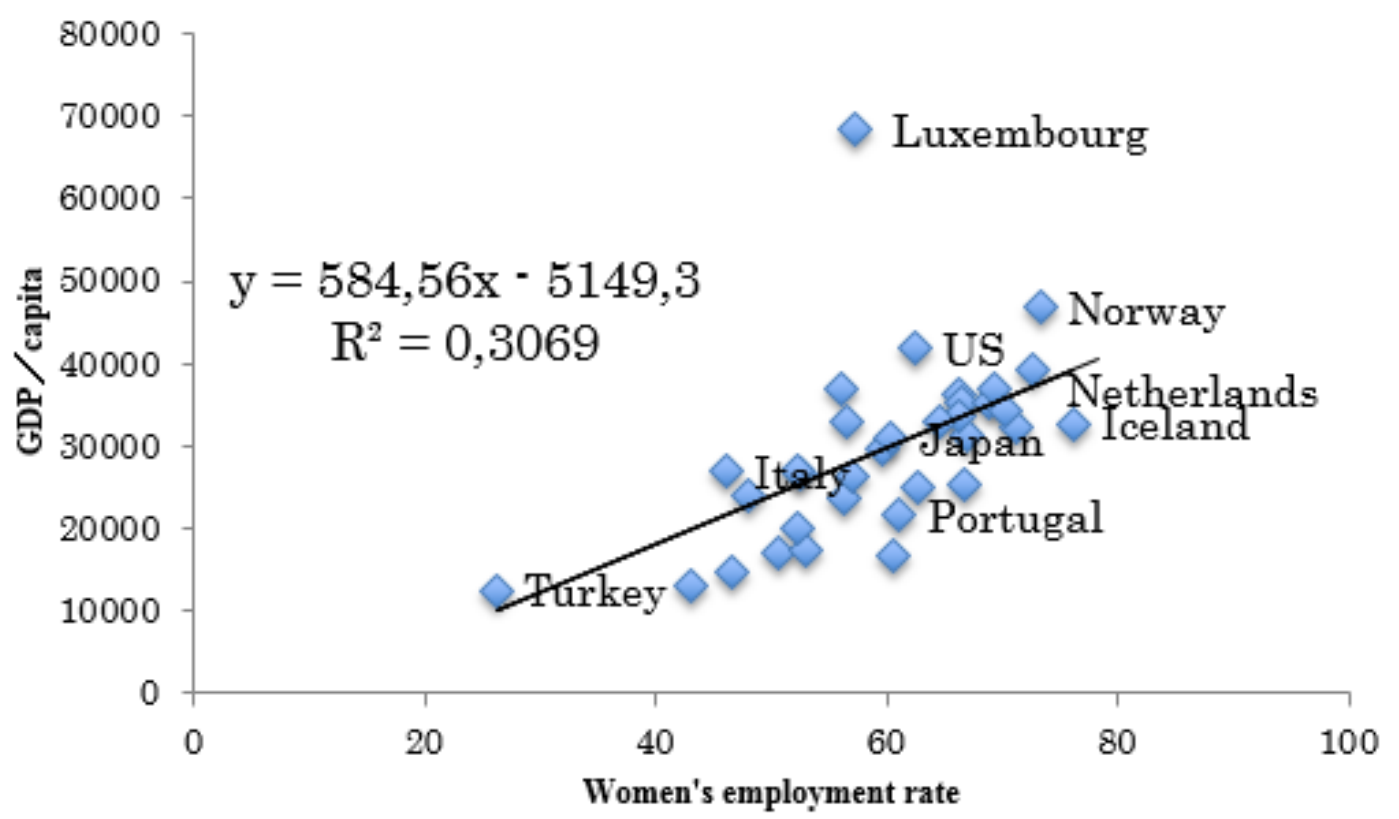

source: calucurated with OECD statistics data 2010

Mckinsey's report "Women's matter 2010" suggested the top-quartile companies in terms of share of women in executive committees from 2007 to 2009 show higher financial performance of this top-quartile companies with all-male executive committees. As for return on equity, the top-quartile group with companies exceeds by 41 percent the group with zero women. In terms of earnings before interest and taxes, the top-quartile companies exceeds by 56 percent. 
Exhibit 4: Companies with a higher proportion of women in their executive committees have better

\section{financial performance ${ }^{3}$}

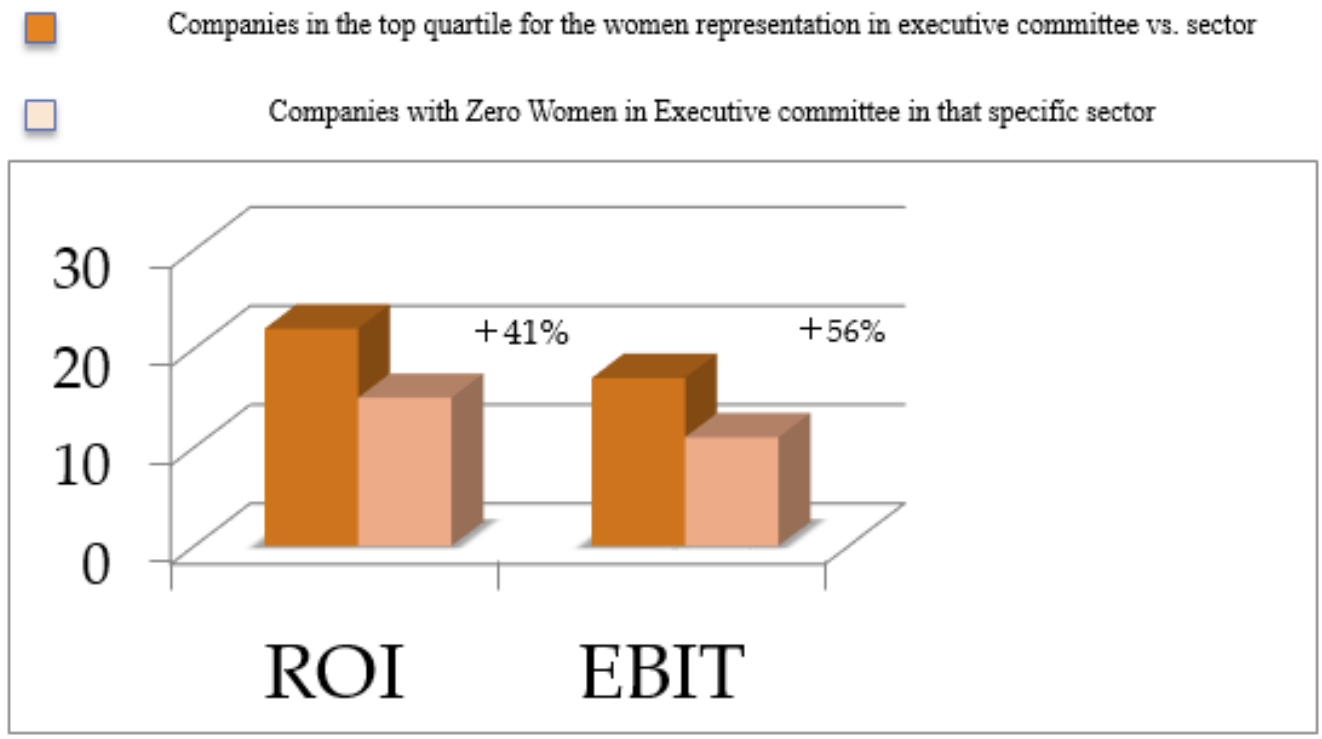

Source: Women's Matter 2010

TSE (Tokyo Stock Exchange) and METI (the Ministry of Economy, Trade and Industry) tackled jointly to designate enterprises that are encouraging women's success in the workplace as "Nadeshiko-brand" in February, 2013. 17 companies was selected as a Nadeshiko-brand.

The Exhibit shows the performance of the top three enterprises (in total 72 stocks) that have high Nadeshiko index among 33 each industry in Tokyo Stock Exchange. "Nadeshiko index" is designated in order to promote the visiblity to what extent companies would encouradge women to play active role in the workplace. Compared with the TOPIX (:Tokyo Stock Price Index), high Nadesiko index enterprises tend to exceeds the performance of the TOPIX and their excess return expands almost consistently year by year.

Through the Nadeshiko Brand and index, METI is aiming to accelerate the efforts of listed companies for encouraging women's success showing that the investors who are interested in improvement of corporate value over medium to long term would like to invest the value added companies that promoting women's success. 
Exhibit5: Performance of the Nadesiko Brand in Tokyo Stock Excnage

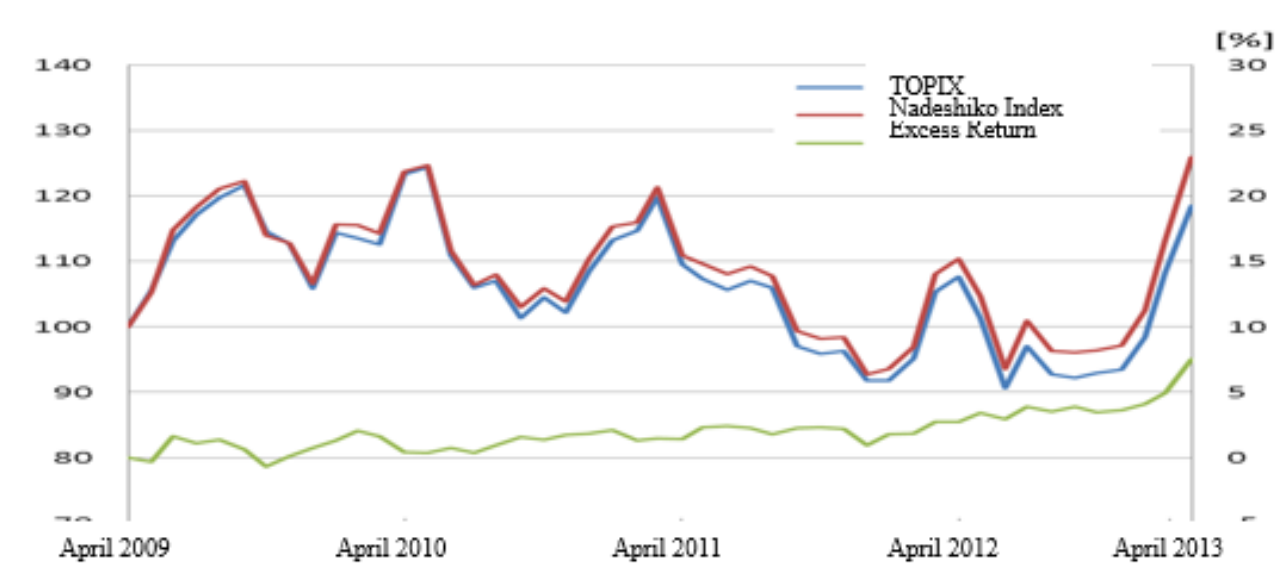

*the excess rate of retur was calculated by subtracting the rate of return on the TOPIX from rate of return index

of 72 stocks on the basis of the April 1, 2009 in the same period.

Source: Japan Cabinet Office Kyodo-Sankaku Number 56 April-May 2013 pp10

The analysis shows the more gender diverse companies tend to have a higher performance than the companies with less gender diversity.

\section{Diversity Triggers Some Innovation}

Companies should utilize the variety of gender, age, ethnic, social and carriers so that they would obtain competitive advantages, foster innovation, minimize risks, and acquire productivity improvement.

In Japan, women are not participating in the labor market well or management positions in workplaces so there is a significant potential that should be pulled out.

By including in the female labor force, the Japanese economy might achieve a remarkable improvement in terms of innovation growth and productivity.

Japan, however, ranked at the bottom of the table of women senior management among 40 economies with just 7 percent occupied by the women according to the repot of Grant Thornton. . Global average of women as percentage of senior management is 24 percent. China is the highest at 51 percent followed by Poland at 48 percent and Latvia 43 percent. The report says countries at top of the table for women in senior management such as China, Latvia, Vietnam, Thailand and the Philippines have high GDP growth for 2012 between 7-8 percent while the bottom eight countries for women in senior management such as Japan, the UK with 19 percent and the USA with 20 percent are also experiencing low levels of growth, with GDP in Japan (1.9\%), the UK (-0.1\%) and the USA (2.2\%) in 2012. In terms of the company's board, G7 countries have just 16 percent of female board members while 26 percent occupied by women in the BRIC economies and 38 percent in the Baltic states.

According to "Equal Employment Opportunity Survey (Equity Research) of Japanese Ministry of Health, Labour and Welfare " in 2011, among the Japanese companies with 10 or more regular employees, $\mathbf{7 8 . 7 \%}$ of the companies have more than one divisions with no or less 
than $10 \%$ female managers. $48.9 \%$ of the companies answered as a reason to no/less female managers "at the moment, there are no women with the knowledge, experience and ability of judgment." In addition, 16.3\% answered "No one meets the enough job tenure to hold a senior position", $15.0 \%$ answered "Women tend to have low seniority and retire before they become managers" .

Exhibit 6: Equal Employment Opportunity Survey

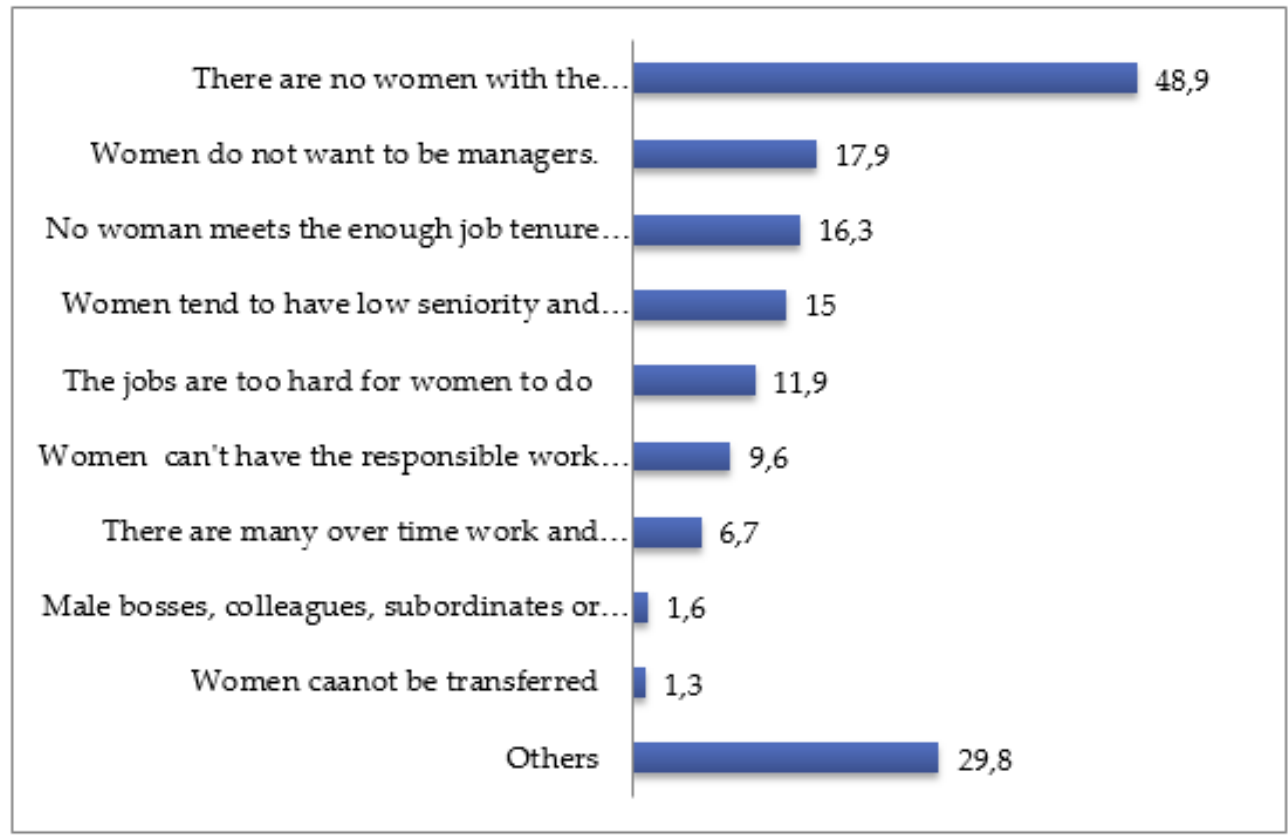

Source: Equal Employment Opportunity Survey, Japanese Ministry of Health, Labour and Welfare, 2011

Why diversity is necessary to the current economy is stemming form the techno-paradigm shift.

Gibbons suggested in his thesis production of knowledge shifted from "Mode1" to "Mode2"

"The old paradigm of scientific discovery ('Mode 1') - characterized by the hegemony of theoretical or, at any rate, experimental science; by an internally-driven taxonomy of disciplines; and by the autonomy of scientists and their host institutions, the universities - was being superseded by a new paradigm of knowledge production ('Mode 2'), which was socially distributed, application-oriented, trans-disciplinary, and subject to multiple accountabilities."

Kodama indicated that innovation patterns shifted from technology breakthrough to technology fusion. "Recent innovations in mechatronics and optoelectronics make it more appropriate to view innovation as the fusion of different type of technology rather than as a series if technology breakthroughs." The techno-paradigm shift requires different abilities from the past. Not only specialized knowledge but also interdisciplinary one will be needed to achieve innovations. Ways of thinking has been changed from Homo to Hetero, from uniform and standardized to diversity.

Valleys of Death or Darwinian Seas is a metaphor which separates research from product development. How to interlock two separated areas where asymmetry of information exists 
would be important for innovation. Among the institutional gaps and variety of stakeholders, management of diversity plays a pivotal role as well.

There are some examples of successful patterns of innovation incorporating management of diversity especially for women. Some product innovation and process innovation have been created by women from the female point of views.

\section{Examples of Product Innovation}

- Nissan moter company, after made an allyance with Renault S.A. of France, the diversity inside the company has increased ethnically and genderlly. The company has promoted diversity management as a business imperative. For instance, one manager becomes in charge of two sections that interests conflict each other. To manage two different contradict business activities, managers would be trained for management of diversity. The company succeeded in developing new car incorporating female's idea. Domestic market is shirinking because of low birth rate and aging society. 74 percent of wives are the decision maker to buy somethings in the family. When you decide to buy a car, 60 percent of decision makers are women, which is more than half. So, the company formed a woman team for to car product development in order to reflect women needs to the design. For instance, Nissan Note adopted the rear seat doors open to 85 degrees so that it is easy to get in and out with children or children in a buggy. You can carry children very quickly and safely. This car achieved the best sales for five consecutive months sales among gasoline cars.

- A Japanese electronics maker, Toshiba corp. started a female managers development program. Ms Fukushima, the member of the inaugural class, was successful in the development of world first glasses free 3D televisions. The company is developing consumer electronics series from female point of views. For instance, capability of refrigerators in retention of vegetables' freshness has been improved well.

- Kirin holdings company involved female staffs in liquor product planning. The staffs hit an idea of non-alcoholic beer women could drink during pregnancy and breastfeeding. Thanks to meet the needs of women, new markets has been uccessfully developed and replaced the shirinking beer market.

\section{Process innovation}

- Tenhiko launched web site for steel sales for overseas making use of female employees who have good English language skills but working as clerical work before. International sales have increased through the internet and a casual type of web design attracted people. The company's amokestack image have changed and people regarded the company as a place that is easy to work. A number of applicants for the company has increased for both men and women from 20 applicants before web site started to exceeded 2000 in fiscal year 2011.

- Start Today Co.Ltd. , the company running internet fashion and clothing mall called "Zozotown", introduced 6-hour work (9:00 to 15:00) for all employees and it contributed to increase a productivity $25 \%$ year-on-year improvement. Women employees rasing up thier children came to feel easy to pick them up at nurseries. 
Some employees go and visit shops to search something in fashon after work which contribute to their business marketing knowledge.

Women engineers who came back to work after childcare leave organized "Customer Care Group ". During the daytime, they visited customers to understand market needs with sensitivities. This activity contributed to the business development after that.

\section{CONCLUSIONS}

The analysis suggested that any companies and enterprises with gender diversity show higher performance than those with less diversity. It is said that diversity might boost economy and many economic indexes show them. Companies in Japan are providing many cases that female employees contributed to product innovation and process innovation. So that incorporating gender diversity might contribute to create innovation. However, rate of the Japanese women who are in the labor market is still low in Japan comparing to world average and rate of the women who are in senior management is still low as well and glass ceilings remain almost all the countries although the number of the female management is increasing in total. In order to enhance the gender diversity, many policy should be accelerated including positive actions.

\section{REFERENCES}

Cabinet Office, white paper on gender equality 2012

Goldmansachs, Equity Research Fortnightly Thoughts Women's Work: Driving the Economy, Issue 53, April 25, 2013

Mckinsey \& Company, Women Matter 2010, Women at the top of the corporations: Making it happen, pp7, 2010

METI, METI Journal "Diversity Management Selection 100" and "Nadeshiko Brand"

-What is "Diversity Management"to Enhance Corporate Competitiveness? , June/ July 2013

Grant Thornton, Grant Thornton International Business Report 2013- Women in senior management:

setting the stage for growth, 2013

Cabinet Office, white paper on gender equality 2013

Michael Gibbons, Camille Limoges, Helga Nowotny, Simon Schwartzman, Peter, The New Production of Knowledge: The Dynamics of Science and Research in Contemporary Societies, Sage Publication, 1994 
Fumio Kodama, Emerging Patterns of Innovation: Source of Japan's Technology Edge, Harvard Business School Press, 1995

Women Matter 2012, Making the Breakthrough, Mckinsey \& Company, 2012

Philip Auerswald and Lewis M. Branscomb, Valleys of Death and Darwinian Seas: Financing the Invention to Innovation Transition in the United States, Journal of Technology Transfer, volume 28, issue 3-4, pages 227-239, 2008

Interview to Mr. Itaru Koeda serves as an Executive Advisor and Honorary Chairman of Nissan Motor Co., Ltd. January 222013 in Tokyo

Mizuho Information and Research Institute, Diversity and promoting Women's activities, Ministry of Economy, Trade and Industry commissioned projects 2011 